\title{
Impact of Bruxism on Oral Health-related Quality of Life among Schoolchildren in Mangaluru City-A Case Control Study
}

\author{
Swapna Sarit ${ }^{1}$, Gururaghavendran Rajesh ${ }^{2}$, Ashwini Rao ${ }^{3}$, Ramya Shenoy ${ }^{4}$, Mithun Pai ${ }^{5}$, Subhajit Routh ${ }^{6}$
}

\begin{abstract}
Aim: The aim of the present study was to assess the impact of bruxism on oral health related quality of life (OHRQoL) among 12 to 15 -year-old school-going children in Mangaluru.

Materials and methods: A case-control study was conducted among 10812 to 15 year-old school-going children in Mangaluru. Cases were identified from children having poor OHRQoL and controls as children having better OHRQoL by selecting median scores using Child Perception Questionnaire $\left(\mathrm{CPQ}_{11-14}\right)$. Bruxism was identified using the criteria of American Association of Sleep Medicine (AASM) questionnaire. Information regarding dental caries, dental wear, and malocclusion were also collected.

Results: Bruxism was significantly associated with OHRQoL subscales such as emotional and social well-being scores, respectively $(p=0.01$ and $p=0.02$ ). Malocclusion also showed statistically significant association with OHRQoL subscale of emotional well-being score. However, there were no significantly significant associations between bruxism and overall mean OHRQoL scores $(p>0.05)$.

Conclusion: Bruxism had statistically significant association with OHRQoL subscales, and was shown to have significant impacts on social and emotional wellbeing of participants. Results indicate that bruxism might affect the psychosocial functioning of children.

Clinical significance: Bruxism is a common clinical condition encountered by clinicians. The results of the present study indicate that it can have a definite and deeper impact on children's emotional health and also on the way they socialize. It can thus be one of the critical predictors of psychosocial functioning of the children.

Keywords: Adolescent, Bruxism, Dental caries, Habits, Malocclusion, Quality of life.

World Journal of Dentistry (2019): 10.5005/jp-journals-10015-1631
\end{abstract}

\section{INTRODUCTION}

"Bruxism is a para-functional habit that occurs involuntarily by contact of the teeth occlusal surfaces except chewing and swallowing food." This includes contact of occlusal surfaces of teeth other than those occurring during chewing and swallowing food. Similarly, other habits that are para-functional, severe teeth grinding is a common problem in children and affects the cervical and cranio-mandibular structures. ${ }^{1}$ The second edition of International Classification of Sleep Disorders, (ICSD) states, Sleep Bruxism (SB) as "an oral para-function characterized by grinding or clenching of the teeth during sleep that is associated with an excessive (intense) sleep arousal activity". It is a most common problem in children and in spite of a lot of research that has been done on its prevalence, effect and management, the cause of sleep bruxism is still unclear. ${ }^{2}$

The occurrence of SB during the initial growth, and development periods might lead to the formation of craniofacial and temporomandibular disorders, like muscular pain, headache, respiratory problems, tooth wear, and impacts an individual's quality of life (QoL) negatively. ${ }^{3,4}$ The prevalence of bruxism varies between different populations. The methods and criteria employed for the diagnosis of bruxism are not uniform across different countries. Etiologic factors implicated in the etiology of sleep bruxism are also myriad. Various factors that might lead to bruxism includes: local, mechanical and systemic factors, neurologic, psychological factors, and genetics. ${ }^{5}$ Current scientific evidence regarding the etiology of sleep bruxism does not provide unequivocal results. Tooth wear and periodic clenching of teeth are the two most common clinical

\begin{abstract}
${ }^{1-6}$ Department of Public Health Dentistry, Manipal College of Dental Sciences, Mangaluru; Manipal Academy of Higher Education, Manipal, Karnataka, India

Corresponding Author: Gururaghavendran Rajesh, Department of Public Health Dentistry, Mangaluru; Manipal College of Dental Sciences, Manipal Academy of Higher Education, Manipal, Karnataka, India, Phone: +91 824-2428716, e-mail: drrajeshgrao@gmail.com
\end{abstract}

How to cite this article: Sarit S, Rajesh G, et al. Impact of Bruxism on Oral Health-related Quality of Life among Schoolchildren in Mangaluru City_A Case Control Study. World J Dent 2019;10(3):235-240.

Source of support: Nil

Conflict of interest: None

signs of bruxism. Tooth mobility, gum recession and inflammation, pain and hypertrophy of masticatory muscles, adverse changes in temporomandibular joint (TMJ), and headache are the other associated side effects. ${ }^{6,7}$ Individuals, who are diagnosed with temporomandibular disorders that include sleep bruxism as well have compromised quality of life and psychological aspects, need definitive care and adequate treatment. ${ }^{8}$

Measures of QoL with respect to oral health provide important information when evaluating the treatment aspects of individuals and populations, making clinical decisions and assessing interventions, services, and programs. ${ }^{9,10}$ Although QoL assessment among individuals with oral health issues has been presented in existing literature, there are very few articles that have explored the 
impact of SB on QoL in children aged 12-15 years. QoL assessment with respect to oral health includes an evaluation of the effect of oral problems from day-to-day in the life of an individual, affecting their psychological and emotional wellbeing.

Although literature linking SB to OHRQoL continues to grow, few studies have examined its impact in adolescents, especially in the Indian context. Keeping this in mind, this study was conceptualized for the determination of the impact of bruxism on OHRQoL among the school going children in Mangaluru.

\section{Materials and Methods}

The present study employed a case-control design. List of all the schools in Mangaluru was obtained from the Block Education Officer. A stratified random sampling technique was employed to select the schools. The schools were stratified as government, private-aided, and private schools. Ethical clearance was obtained from the Institutional Ethics Committee (IEC). (Protocol Ref no.16045).

A pilot survey was carried out among 35 school-going children aged 12-15 years in Mangaluru. The total study population consisted of 108 school-going children. A sample size of minimum 32 study subjects (cases) for each domain was calculated according to the findings of the pilot study using G Power software (version 3.1.2, Denmark) with an effect size of 0.5 and with $95 \% \mathrm{Cl}$ (confidence interval) and keeping the power of the study at $80 \%$. Also, the minimum ratio of cases and controls was kept at 1:1.

The cases were categorized as those with high and low OHRQoL based on the median OHRQoL scores as obtained by $C P Q_{11-14}$. The median value of OHRQoL was thus employed to dichotomize the cases as those with high and low OHRQoL scores. Subgroup analysis for each of the four domains of OHRQoL was also performed. Subjects were classified as high and low OHRQoL scores for each of the four domains based on the median scores for the particular domain.

Inclusion criterion for the present study was school children aged 12-15 years. Participants not willing to give parents' written informed consent and their own assent and children suffering from any systemic diseases constituted the exclusion criteria. Data collection was completed over a period of 6 months from June to November 2016.

The questionnaire was translated to the local language (Kannada) by the first translator and back translated to the English language by a second translator. The final version of the questionnaire in Kannada was then finalized by the investigators and the two translators. Before the commencement of the main study, the questionnaires were administered to the study participants, which were not included in the final study. The questionnaire was validated with 35 children before administration after obtaining approval from IEC. The questionnaire was given to five subject experts who assessed the comprehensibility, relevance, and appropriateness of the questionnaire. ${ }^{11}$ Reliability of the questionnaire was assessed by employing Cronbach's alpha. Calibration of the examiner was done to establish inter examiner reliability, which was assessed by employing the Kappa statistic. Based on the pilot study, Kappa statistic was found to be 0.9 , which suggests good agreement.

Demographic details, medical history, and the dental attendance pattern of the study subjects were obtained from their parents by using the questionnaire method. Symptoms and signs of bruxism were assessed by using screening questionnaire recommended by AASM and detailed clinical examination for bruxism, respectively. The questionnaire consists of eight questions with yes/no response. OHRQoL was measured by the 16-item version of $C P Q_{11-14}$. Malocclusion was evaluated by focusing on dental appearance using the Dental Aesthetic Index (DAI).

Data analysis was done using the Statistical Package for Social Sciences (SPSS), version 11.5 (SPSS Inc, Chicago IL). Likelihood Ratio test and Chi-square test were used to determine the association between Bruxism and OHRQoL among school children in Mangaluru. Using this method, variables that showed a statistically significant difference at the $95 \%$ level $(p<0.05)$ were selected.

\section{Results}

The total study population consisted of 108 school-going children. A sample size of minimum 32 study subjects (cases) for each domain was calculated according to the findings of the pilot study. Mean age of the population was $14.21 \pm 0.81$ years. There were 74 boys and 34 girls. Association of Overall OHRQoL scores with various variables such as bruxism, tooth wear, malocclusion, and dental caries are presented in Table 1. It is observed that there is no statistically significant association between any of the variables with overall score of OHRQoL.

The association of domains of OHRQoL with various variables has been presented. The results indicate that there is no impact of any variable on the oral symptom and functional limitation domains of OHRQoL (Tables 2 and 3). It can be observed that bruxism was significantly associated with the domain related to emotional wellbeing $(p<0.05$, odds ratio(OR) $=3.03$, and $\mathrm{Cl} 1.32-6.96)$. The results also indicate that malocclusion had a significant association with emotional well-being domain of $\mathrm{OHRQOL}(p<0.05, \mathrm{OR}=0.08$, and $\mathrm{Cl}$ 0.01-0.76) (Table 4).

Chi-square analysis also indicated that bruxism was significantly associated with social well-being score of OHRQoL $(p<0.05$, $\mathrm{OR}=2.84$, and $\mathrm{Cl}$ 1.24-6.49) (Table 5). There were no statistically significant associations between any other variables and OHRQOL of the study participants.

\section{Discussion}

The present study was undertaken to determine the impact of bruxism on OHRQoL among school children in Mangaluru. Bruxism is a common oral health problem that is widely prevalent in the population, especially among children. It might have a definite impact on an individual's QoL and their social life as well. There are very few studies in literature that have explored the potential impact of bruxism on OHRQoL, especially in the Indian context. OHRQoL instruments help in supplementing the information obtained by clinical indicators. ${ }^{12}$ They help in addressing the psycho-social effects of oral complications and provide a holistic approach to patient care. ${ }^{13}$

Cross-sectional study design has been employed in majority of studies to address the current issue, but these elements do not allow inference of causality. ${ }^{111,14,15}$ The present study employed a case-control design, which allows the determination of the strength of the relationship between an event and risk factors. Such study designs also help in controlling the confounding variables and allow the accurate estimation of precision and power of the study. ${ }^{16,17}$

The results of the present study indicate bruxism was significantly associated with the domain related to the emotional well-being of OHRQoL $(p=0.01)$. It can also be observed that malocclusion was significantly associated with the domain related to the emotional well-being $(p=0.01)$. These findings are in corroboration with the results given by Carvalho et al., among 
Table 1: Association of overall score (OHRQoL) with various variables

\begin{tabular}{|c|c|c|c|c|c|}
\hline & Total $(n=108)$ & Cases $(n=38)$ & Controls $(n=70)$ & & \\
\hline Children & $n(\%)$ & $n(\%)$ & $n(\%)$ & OR $(95 \% \mathrm{Cl})$ & pvalue \\
\hline Mean age $(\mathrm{SD})^{\ddagger}$ & $14.15(0.86)$ & $14.03(0.94)$ & $14.21(0.81)$ & & 0.32 \\
\hline \multicolumn{6}{|l|}{ Gender** } \\
\hline Males & $74(68.5)$ & $24(63.2)$ & $50(71.4)$ & $0.68(0.29-1.58)$ & 0.39 \\
\hline Females & 34 (31.5) & $14(36.8)$ & $20(28.6)$ & & \\
\hline \multicolumn{6}{|l|}{ Bruxism** } \\
\hline Present & $36(33.3)$ & $14(36.8)$ & $22(31.4)$ & $1.27(0.55-2.91)$ & 0.67 \\
\hline Absent & $72(66.7)$ & $24(63.2)$ & $48(68.6)$ & & \\
\hline \multicolumn{6}{|l|}{ Tooth wear** } \\
\hline Present & $16(14.8)$ & $6(15.8)$ & $10(14.3)$ & $0.88(0.29-2.66)$ & 0.52 \\
\hline Absent & $92(85.2)$ & $32(84.2)$ & $60(85.7)$ & & \\
\hline \multicolumn{6}{|l|}{ Malocclusion ${ }^{* *}$} \\
\hline No abnormality & $101(93.5)$ & $35(92.1)$ & $66(94.3)$ & $0.7(0.15-3.33)$ & 0.69 \\
\hline Definite/severe/very severe malocclusion & $7(6.5)$ & $3(7.9)$ & $4(5.7)$ & & \\
\hline \multicolumn{6}{|l|}{ Dental caries ${ }^{* *}$} \\
\hline Present & $41(38)$ & $13(34.2)$ & $28(40)$ & $1.28(0.56-2.92)$ & 0.67 \\
\hline Absent & $67(62)$ & $25(65.8)$ & $42(60)$ & & \\
\hline
\end{tabular}

FStudent $t$ test.

${ }^{* *}$ Chi square test, $\mathrm{OR}$-odds ratio, $\mathrm{Cl}$-confidence interval

Table 2: Association of oral symptoms score (OHRQoL) with various variables

\begin{tabular}{|c|c|c|c|c|c|}
\hline & Total $(n=108)$ & Cases $(n=50)$ & Controls $(n=58)$ & & \\
\hline Children & $n(\%)$ & $n(\%)$ & $n(\%)$ & OR $(95 \% C l)$ & $p$ value \\
\hline \multicolumn{6}{|l|}{ Bruxism** } \\
\hline Present & $36(33.3)$ & $17(34)$ & $19(32.8)$ & $1.05(0.47-2.35)$ & 0.52 \\
\hline Absent & $72(66.7)$ & $33(66)$ & $39(67.2)$ & & \\
\hline \multicolumn{6}{|l|}{ Tooth wear** } \\
\hline Present & $16(14.8)$ & $6(12)$ & $10(17.2)$ & $1.52(0.51-4.55)$ & 0.31 \\
\hline Absent & $92(85.2)$ & $44(88)$ & $48(82.8)$ & & \\
\hline \multicolumn{6}{|l|}{ Malocclusion ${ }^{* *}$} \\
\hline No abnormality & $101(93.5)$ & $48(96)$ & $53(91.4)$ & $2.26(0.42-12.2)$ & 0.33 \\
\hline Definite/severe/very severe malocclusion & $7(6.5)$ & $2(4)$ & $5(8.6)$ & & \\
\hline \multicolumn{6}{|c|}{ Dental caries** } \\
\hline Present & $41(38)$ & $22(44)$ & $19(32.8)$ & $0.62(0.28-1.35)$ & 0.24 \\
\hline Absent & $67(62)$ & $28(56)$ & $39(67.2)$ & & \\
\hline
\end{tabular}

${ }^{* *}$ Chi square test, $\mathrm{OR}$-odds ratio, $\mathrm{Cl}$-confidence interval

children aged $11-14$ years in Brazil. ${ }^{15}$ Bruxism is associated with psycho-emotional and/or systemic problems. Social-demographic, psycho-social, and lifestyle factors can influence the behavior of participants with respect to general health at any phase of life. ${ }^{18,19}$

The results also indicate that bruxism was significantly associated with social well-being domain of OHRQoL $(p=0.02)$. These findings are similar as reported in the studies done by Bendo et al. and O'brien et al. ${ }^{20,21}$ The social well-being domain addresses social co-existence issues like avoiding smiling or laughing in public, arguing with another pupil or family member, or the child being the subject to funny nicknames on account of her/his dentition, and other orofacial structures. The age group included in this present study might have better perception about OHRQoL and may possess the capacity to make judgments on their social well-being. ${ }^{22,23}$

However, no association was observed between other variables such as tooth wear and dental caries on any domain of the OHRQoL. Bruxism also had no impact on the overall scores of OHRQoL or on any of the domain subscales. These findings are in agreement with those reported by Antunes et al., and Castelo.,12

The results also indicate that higher socio-economic status was a protective factor for the negative impact on the OHRQoL of schoolchildren suffering from bruxism. Inflammatory oral diseases may be more frequent in populations belonging to lower socio-economic group. This could have a definite impact on their QoL. The present study results have similar findings presented in other surveys that evaluated QoL in schoolchildren of the similar age groups. ${ }^{1,15}$ However, this study results are not in corroboration with the findings reported by Nurelhuda et al., among 12-year-old schoolchildren in Sudan. ${ }^{24}$

The increased impact on OHRQoL is associated with clinical conditions with oral problems. There was a positive association of better OHRQoL in children, with a good general health and these results are in agreement with those presented by Liu et al. and Serra-Negra et al. ${ }^{25,26}$

The diagnosis of bruxism was carried out on the self-report measures, which is in accordance with the criteria proposed by 
Bruxism and Quality of Life: Case Control Study

Table 3: Association of functional limitation score (OHRQoL) with various variables

\begin{tabular}{|c|c|c|c|c|c|}
\hline \multirow[b]{2}{*}{ Children } & Total $(n=108)$ & Cases $(n=52)$ & Controls $(n=56)$ & \multirow[b]{2}{*}{ OR $(95 \% \mathrm{Cl})$} & \multirow[b]{2}{*}{$p$ value } \\
\hline & $n(\%)$ & $n(\%)$ & $n(\%)$ & & \\
\hline \multicolumn{6}{|l|}{ Bruxism** } \\
\hline Present & $36(33.3)$ & $20(38.5)$ & $16(28.6)$ & $1.56(0.69-3.49)$ & 0.31 \\
\hline Absent & $72(66.7)$ & $32(61.5)$ & $40(71.4)$ & & \\
\hline \multicolumn{6}{|l|}{ Tooth wear** } \\
\hline Present & $16(14.8)$ & $8(15.4)$ & $8(14.3)$ & $0.91(0.31-2.65)$ & 0.54 \\
\hline Absent & $92(85.2)$ & $44(84.6)$ & $48(85.7)$ & & \\
\hline \multicolumn{6}{|l|}{ Malocclusion ${ }^{* *}$} \\
\hline No abnormality & $101(93.5)$ & $48(92.3)$ & $53(94.6)$ & $0.67(0.14-3.19)$ & 0.7 \\
\hline Definite/severe/very severe malocclusion & $7(6.5)$ & $4(7.7)$ & $3(5.4)$ & & \\
\hline \multicolumn{6}{|l|}{ Dental caries** } \\
\hline Present & $41(38)$ & $20(38.5)$ & $21(37.5)$ & $0.96(0.44-2.08)$ & 0.53 \\
\hline Absent & $67(62)$ & $32(61.5)$ & $35(62.5)$ & & \\
\hline
\end{tabular}

Table 4: Association of emotional well-being score (OHRQoL) with various variables

\begin{tabular}{|c|c|c|c|c|c|}
\hline \multirow[b]{2}{*}{ Children } & Total $(n=108)$ & Cases $(n=41)$ & Controls $(n=67)$ & \multirow[b]{2}{*}{ OR $(95 \% C l)$} & \multirow[b]{2}{*}{$p$ value } \\
\hline & $n(\%)$ & $n(\%)$ & $n(\%)$ & & \\
\hline \multicolumn{6}{|l|}{ Bruxism** } \\
\hline Present & $36(33.3)$ & $20(48.8)$ & $16(23.9)$ & $3.03(1.32-6.96)$ & $0.01 *$ \\
\hline Absent & $72(66.7)$ & $21(51.2)$ & $51(76.1)$ & & \\
\hline \multicolumn{6}{|l|}{ Tooth wear** } \\
\hline Present & $16(14.8)$ & $8(19.5)$ & $8(11.9)$ & $0.55(0.19-1.62)$ & 0.21 \\
\hline Absent & $92(85.2)$ & $33(80.5)$ & $59(88.1)$ & & \\
\hline \multicolumn{6}{|l|}{ Malocclusion** } \\
\hline No abnormality & $101(93.5)$ & $35(85.4)$ & $66(98.5)$ & $0.08(0.01-0.76)$ & $0.01^{*}$ \\
\hline Definite/severe/very severe malocclusion & $7(6.5)$ & $6(14.6)$ & $1(1.5)$ & & \\
\hline \multicolumn{6}{|l|}{ Dental caries $* *$} \\
\hline Present & $41(38)$ & $17(41.5)$ & $24(35.8)$ & $0.78(0.35-1.74)$ & 0.68 \\
\hline Absent & $67(62)$ & $24(58.5)$ & $43(64.2)$ & & \\
\hline
\end{tabular}

**Chi square test

${ }^{*} p<0.05, \mathrm{OR}-$ odds ratio, $\mathrm{Cl}$-confidence interval

Table 5: Association of social well-being scores (OHRQoL) with various variables

\begin{tabular}{|c|c|c|c|c|c|}
\hline \multirow[b]{2}{*}{ Children } & Total $(n=108)$ & Cases $(n=42)$ & Controls $(n=66)$ & \multirow[b]{2}{*}{ OR $(95 \% C l)$} & \multirow[b]{2}{*}{$p$ value } \\
\hline & $n(\%)$ & $n(\%)$ & (\%) & & \\
\hline \multicolumn{6}{|l|}{ Bruxism** } \\
\hline Present & $36(33.3)$ & $20(47.6)$ & $16(24.2)$ & $2.84(1.24-6.49)$ & $0.02^{*}$ \\
\hline Absent & $72(66.7)$ & $22(52.4)$ & $50(75.8)$ & & \\
\hline \multicolumn{6}{|l|}{ Tooth wear** } \\
\hline Present & $16(14.8)$ & $8(19)$ & $8(12.1)$ & $0.58(0.2-1.7)$ & 0.23 \\
\hline Absent & $92(85.2)$ & $34(81)$ & $58(87.9)$ & & \\
\hline \multicolumn{6}{|l|}{ Malocclusion** } \\
\hline No abnormality & $101(93.5)$ & $38(90.5)$ & $63(95.5)$ & $0.45(0.09-2.13)$ & 0.42 \\
\hline Definite/severe/very severe malocclusion & $7(6.5)$ & $4(9.5)$ & $3(4.5)$ & & \\
\hline \multicolumn{6}{|c|}{ Dental caries ${ }^{* *}$} \\
\hline Present & $41(38)$ & $17(40.5)$ & $24(36.4)$ & $0.84(0.38-1.86)$ & 0.68 \\
\hline Absent & $67(62)$ & $25(59.5)$ & $42(63.6)$ & & \\
\hline
\end{tabular}

${ }^{* *}$ Chi square test

${ }^{*} p<0.05$, OR—odds ratio, $\mathrm{Cl}$-confidence interval 
AASM. ${ }^{27}$ Further studies have to be conducted to explore the potential role of alternate diagnostic criteria such as electromyography and polysomnography that are considered as gold standard for this diagnosis. The usage of the above mentioned additional criteria might help in better epidemiological viability to the findings. The present study can provide valuable baseline information for further studies on various aspects of bruxism. It can be of assistance to patients, as it can pave the way for providing better quality of life. ${ }^{15}$ There are very few studies that have adopted a matched case control design to explore the impact of bruxism on OHRQoL. The case control design is more robust than the conventional descriptive analysis. The present study might give crucial insights into the pathways by which bruxism impacts OHRQoL. The present study was conducted among school children in the community, and the findings have important implications for child oral health and OHRQoL.

The findings of the present study have to be viewed in light of its limitations. Employing self-reported measures for bruxism and questionnaire for OHRQoL are its important limitations. Yessaying bias, social desirability/faking good bias, and deviation/ faking bad bias can influence the outcomes of any questionnaire based studies. ${ }^{28}$ The results from investigations from one particular geographical area are fraught with its inherent limitations of extrapolations and generalizations.

\section{Conclusion}

Bruxism had significant impact on OHRQoL subscales namely the emotional well-being and the social well-being domains. Malocclusion was significantly associated with the emotional well-being domain of OHRQoL. Our results indicate that bruxism may have an impact on psycho-social functioning of children. One of the strengths of the present study is its design. Information gleaned from the case-control study design is more robust and reliable than conventional and frequently reported descriptive surveys in the existing literature. The present study has definite clinical implications regarding care of children with bruxism. One has to bear in mind that bruxism can have a deeper impact on emotions and socializing patterns of children. The present study also highlights the policy implications pertaining to bruxism. Preventive and corrective measures for bruxism among children are critical for their psychosocial well-being.

\section{References}

1. Castelo PM, Barbosa TS, et al. Quality of life evaluation of children with sleep bruxism. BMC Oral Health 2010;10(16):1-7. DOI: 10.1186/14726831-10-16.

2. Masuko AH, Villa TR, et al. Prevalence of bruxism in children with episodic migraine- a case-control study with polysomnography. BMC Research Notes 2014;7(298):1-4. DOI: 10.1186/1756-0500-7-298.

3. Seraj B, Shahrabi M, et al. The Prevalence of Bruxism and Correlated Factors in Children Referred to Dental Schools of Tehran, Based on Parents' Report. Iran J Pediatr 2010;20(42):174-180.

4. Negra JM, Paiva SM, et al. Relationship between Tasks Performed, Personality Traits, and Sleep Bruxism in Brazilian School Children - A Population Based Cross-Sectional Study. PLoS One 2013;8(11):1-6.

5. Lobbezoo F, Ahlberg J, et al. Bruxism defined and graded: an international consensus. J Oral Rehabil 2013;40(1):2-4. DOI: 10.1111/ joor.12011.

6. Locker D. Disparities in oral health-related quality of life in a population of Canadian children. Community Dent Oral Epidemiol 2007;35(5):348-356. DOI: 10.1111/j.1600-0528.2006.00323.x.

7. Manfredini D, Restrepo C, et al. Prevalence of sleep bruxism in children: a systematic review of the literature. J Oral Rehabil 2013;40(8):631-642. DOI: 10.1111/joor.12069.
8. Barbosa TS, Leme MS, et al. Evaluating oral health-related quality of life measure for children and preadolescents with temporomandibular disorder. Health Qual Life Outcomes 2011;9:32. DOI: 10.1186/14777525-9-32.

9. Aguilar-Díaz FC, Irigoyen-Camacho ME, et al. Oral-health-related quality of life in schoolchildren in an endemic fluorosis area of Mexico. Qual Life Res 2011;20(10):1699-1706. DOI: 10.1007/s11136-011-9897-4.

10. Kumar S, Kroon J, et al. A systematic review of the impact of parental socio-economic status and home environment characteristics on children's buccal health related quality of life. Health Qual Life Outcomes 2014;12:41-56. DOI: 10.1186/1477-7525-12-41.

11. Health measurement scales: A practical guide to their development and use (5th edition). Aust N Z J Public Health 2016;40:294-295. DOI: 10.1111/1753-6405.12484.

12. Antunes LA, Castilho T, et al. Childhood bruxism: Related factors and impact on oral health-related quality of life. Spec Care Dentist 2016;36(1):7-12. DOI: 10.1111/scd.12140.

13. Antunes $L A A$, Leão $A T$, et al. The impact of dental trauma on quality of life of children and adolescents: a critical review and measurement instruments. Cien Saude Colet 2012;17(12):3417-3424. DOI: 10.1590/ S1413-81232012001200026.

14. Insana SP, Gozal D, et al. Community based study of sleep bruxism during early childhood. Sleep Med 2013;14(2):183-188. DOI: 10.1016/ j.sleep.2012.09.027.

15. Carvalho AM, Lima MD, et al. Bruxism and Quality of Life in schoolchildren aged 11 to 14. Cien Saude Colet 2015;20(11):33853393. DOI: 10.1590/1413-812320152011.20772014.

16. Firmino RT, Gomes MC, et al. Case-control study examining the impact of oral health problems on the quality of life of the families of pre-schoolers. Braz Oral Res 2016;30(1):e121. DOI: 10.1590/18073107bor-2016.vol30.0121.

17. Serra-Negra JM, Paiva SM, et al. Environmental factors, sleep duration, and sleep bruxism in brazilian schoolchildren: a case-control study. Sleep Med 2014;15(2):236-239. DOI: 10.1016/j.sleep.2013.08.797.

18. Kiyak HA. Does orthodontic treatment affect patients' quality of life? J Dent Educ 2008;72(8):886-894.

19. Costa AA, Ferreira MC, et al. Impact of wearing fixed orthodontic appliances on oral health-related quality of life among Brazilian children. J Orthod 2011;38:275-281. DOI: 10.1179/14653121141632.

20. O'brien C, Benson PE, et al. Evaluation of a quality of life measure for children with malocclusion. J Orthod 2007;34(3):185-193. DOI: 10.1179/146531207225022185.

21. Bendo CB, Paiva SM, et al. Association between treated/ untreated traumatic dental injuries and impact on quality of life of Brazilian schoolchildren. Health Qual Life Outcomes 2010;8:114. DOI: 10.1186/1477-7525-8-114.

22. Page LA, Boyd D, et al. Do we need more than one Child Perceptions Questionnaire for children and adolescents? BMC Oral Health 2013;13(26):1-7.

23. Jokovic $A$, Locker $D$, et al. Validity and reliability of a questionnaire for measuring child oral-health-related quality of life. J Dent Res 2002;81:459-463. DOI: 10.1177/154405910208100705.

24. Nurelhuda NM, Ahmed MF, et al. Evaluation of oral health-related quality of life among Sudanese schoolchildren using ChildOIDP inventory. Health Qual Life Outcomes 2010;8:152-164. DOI: 10.1186/1477-7525-8-152.

25. Liu LJ, Xiao W, et al. Generic and oral quality of life is affected by oral mucosal diseases. BMC Oral Health 2012;12:2. DOI: 10.1186/14726831-12-2.

26. Serra-Negra JM, Tirsa-Costa $D$, et al. Evaluation of parents/guardian knowledge about the bruxism of their children: family knowledge of bruxism. J Indian Soc Pedod Prev Dent 2013;31(3):153-158. DOI: 10.4103/0970-4388.117965.

27. American Academy of Sleep Medicine. International classification of sleep disorders revised: diagnostic and coding manual. Chicago: American Academy of Sleep Medicine; 2001.

28. Streiner DL, Norman GR, et al. Health measurement scales: a practical guide to their development and use. USA: Oxford University Press; 2014 Oct 30. 


\section{Questionnaires}

Bruxism Questionnaire by American Academy of Sleep Medicine

In the past 6 months, how often have you had the experience of following events? Answer in Yes/No only. There is only one option for each question.

\begin{tabular}{ll}
\hline S. No $\quad$ Item & Yes \\
\hline $1 \quad$ Are you aware, or has anyone heard you, grinding your \\
teeth frequently during sleep? \\
Are you aware that your dentition is worn down more \\
than it should be? \\
Are you aware of any of the following symptoms upon \\
awakening? \\
a Sensation of fatigue, tightness or soreness of your \\
$\quad$ jaw upon awakening? \\
b Feeling that your teeth are clenched or that your \\
$\quad$ mouth is sore upon awakening? \\
c Aching of your temples upon awakening? \\
d Difficulty in opening your mouth wide upon \\
$\quad$ awakening? \\
e Feeling of tension in your jaw joint upon awakening \\
$\quad$ and feeling as if you have to move your lower jaw to \\
$\quad$ release it? \\
f Hearing or feeling a "click" in your jaw joint upon \\
$\quad$ awakening that disappears afterwards?
\end{tabular}

Thank You

\section{Child Perception Questionnaire}

In the past 3 months, how often have you had the following experiences because of your teeth/mouth?

Tick the option that you feel is more appropriate. There is only one option for each question.

\begin{tabular}{|c|c|c|c|c|c|c|}
\hline S. No & Item & Never & Once/Twice & Sometimes & Often & Everyday \\
\hline 1 & Pain in teeth/mouth? & & & & & \\
\hline 2 & Bad breath? & & & & & \\
\hline 3 & Mouth sores? & & & & & \\
\hline 4 & Food caught between teeth? & & & & & \\
\hline 5 & $\begin{array}{l}\text { Difficulty drinking/eating hot/cold } \\
\text { foods? }\end{array}$ & & & & & \\
\hline 6 & Difficulty chewing firm foods? & & & & & \\
\hline 7 & Difficulty in saying words? & & & & & \\
\hline 8 & Taking longer to eat a meal? & & & & & \\
\hline 9 & Been upset? & & & & & \\
\hline 10 & Felt irritable/frustrated? & & & & & \\
\hline 11 & Felt shy? & & & & & \\
\hline 12 & $\begin{array}{l}\text { Concerned what people think about } \\
\text { your teeth/mouth? }\end{array}$ & & & & & \\
\hline 13 & Asked questions? & & & & & \\
\hline 14 & Teased/called names? & & & & & \\
\hline 15 & Avoided smiling/laughing? & & & & & \\
\hline 16 & Argued with children/family? & & & & & \\
\hline
\end{tabular}

\section{Thank You}

